\title{
Synchronous Prostate Cancer and Non-Small Cell Lung Cancer: A Case Report
}

\section{Senkron Prostat Kanseri ve Küçük Hücreli Dışı Akciğer Kanseri: Olgu Sunumu}

\author{
Ela Delikgöz Soykut ${ }^{1}$, Hasan Cem Mısırlığlu ${ }^{2}$, Yıldız Yükselen Güney ${ }^{2}$ \\ ${ }^{1}$ Erzurum Bölge Eğitim Ve Araştırma Hastanesi, Radyasyon Onkolojisi Kliniği, Erzurum \\ ${ }^{2}$ Ankara Dr. Abdurrahman Yurtaslan Onkoloji Eğitim Ve Araştırma Hastanesi, Radyasyon Onkolojisi Kliniği, \\ Ankara \\ DOI: $10.5505 /$ aot.2012.76476
}

\section{ÖZET}

Son zamanlarda yaşam beklentisinin uzaması ve kanser tedavisindeki ilerlemelere bağlı erken tanı olanakları sayesinde birden fazla senkron veya metakron malignite tespiti giderek artmaktadır. Eş zamanlı olarak iki ayrı primer malignite saptandığında tedavi önceliği tümörlerin ciddiyetine göre belirlenmektedir. Primer prostat ve akciğer kanserinin birlikte görülmesi nadirdir. Burada senkron prostat ve akciğer kanser tanılı olgu sunuldu.

Anahtar Kelimeler: Neoplazm; Multipl Primer; Prostat kanseri; Küçük Hücreli Dışı Akciğer Karsinomu

\begin{abstract}
Nowadays, the diagnosis of synchronous and metachronous malignancies are increasing due to extended lifetime expectancy and advances in cancer diagnosis and therapy. When simultaneously multiple primary tumors are detected, treatment priority is determined according to the severity of each tumor. Synchronous primary prostate and lung cancer is rare. Herein, a case with synchronous prostate and lung cancer is presented.
\end{abstract}

Key words: Neoplasms; Multiple Primary; Prostate Cancer; Non-Small Cell Lung Carcinoma

\section{Giriș}

Son zamanlarda yaşam beklentisinin uzamas1 ve kanser tedavisindeki ilerlemelere bağl1 erken tanı olanakları sayesinde birden fazla senkron veya metakron malignite tespiti giderek artmaktadır. Aynı kişide birden fazla primer kanser gelişimi nadir görülen bir durumdur, sıklığı \%1.7 ile \%4.6 arasında değişmekteyken, akciğer kanseri ile birlikte sekonder malignite görülme sıklığ $\% 3$ ile \%13.4 arasında saptanmaktadır (1). Eş zamanlı olarak iki ayrı primer malignite saptandığında tedavi önceliği tümörlerin ciddiyetine göre belirlenir (2). Burada, senkron primer prostat kanseri ve akciğer kanseri tanısı alan, otuz üç aylık takip süresi boyunca her iki malignitesi açısından tam yanıt alınmış bir olgu anlatılmaktadır.

\section{Olgu Sunumu}

Yetmiş yedi yaşında erkek hasta sık idrara çıkma şikayeti ile dış merkezde üroloji kliniğine başvuruyor. Yapılan tetkiklerinde PSA yüksekliği (39 $\mathrm{ng} / \mathrm{mL})$ tespit edilmesi üzerine yapilan prostat biyopsi sonucu prostatik adenokarsinom olarak raporlanıyor. Tümör sağ ve sol kayıtlı materyallerin her ikisinde de mevcut olup, Gleason skoru ise 4+5:9 olarak raporlanıyor. Pelvik manyetik rezonans görüntülemede (MRG) prostat normalden büyük ve içerisinde kalsifikasyonlar olan düzensiz konturlu yapıda olduğu görülüyor. Çekilen tüm vücut kemik sintigrafisinde dejeneratif değişiklikler dışında patolojik bulgu saptanmiyor. D'Amico sinıflamasına göre hasta yüksek risk grubu olarak sınıflandırılıyor. Hastaya uzun süreli androjen blokaji için hormonoterapi başlanarak radyoterapi (RT) açısından değerlendirilmek üzere kliniğimize refere ediliyor.

Klinik içi değerlendirmede başlanan hormonoterapiye iki ay devam edilmesi, sonrasında pelvik RT uygulanması kararı verildi. Hastamızın bu dönemde öksürük şikayeti oldu, çekilen akciğer grafisinde kitle görülmesi üzerine ileri tetkik istendi. Toraks 
bilgisayarlı tomografi (BT) incelemesinde sağ akciğer üst lob apikal segmentte $4 \times 3 \mathrm{~cm}$ boyutunda spiküler kitle izlendi (Resim 1a-1b). Tanı amaçlı yapılan bronkoskopik incelemede endobronşial oluşum gözlenmedi.

Transtorasik ince iğne aspirasyon biyopside patoloji sonucu küçük hücreli diş1 akciğer karsinomu, alt tip olarak adenokarsinom şeklinde raporlandi. İmmünhistokimyasal incelemede tümör hücrelerinde CK7, TTF-1 ve mCEA ile diffüz boyanma, HMWCK ile fokal boyanma görülmüş, müsikarmin ile boyanma olmamıştır. Metastaz taraması için yapılan pozitron emisyon tomografi/ bilgisayarlı tomografi incelemesinde sternumda sternotomi defekti, sağ akciğerde üst lobda yumuşak doku alanında patolojik artmış fluorodeoksiglukoz (FDG) tutulumu (maksimum standardize uptake volume) (SUVm: 7.87) ve prostat bezinde patolojik artmış FDG tutulumu (SUVm: 11.96) gözlendi. Özgeçmişinde geçirilmiş koroner arter by-pass operasyonu öyküsü olan hastanın hipertansiyon, diyabet, kronik böbrek hastalığı tanıları mevcuttu. Kırk paket/yıl sigara kullanımı öyküsü olan hasta akciğer kanseri tanısı ile sigara kullanmayı bıraktı. Erken evre akciğer kanseri tanısı alan hastamız anestezi konsültasyonunda operasyon açısından yüksek riskli olarak değerlendirildi.

Çift primer kanser tanısı alan hastanın tedavisine öncelikle daha agresif seyirli olan akciğer kanseri tedavisi ile başlanması kararı alındı. Eşlik eden komorbid hastalıklar ve ileri yaş nedeni ile medikal olarak inoperabl olan hastada toraksa RT endikasyonu kondu. Bu esnada daha önce prostat kanseri tedavisi için verilmiş olan karara uyularak hormonoterapi uygulanmasina ( 2 ay yerine 6 ay), ardindan ise pelvik RT yapılmasına karar verildi. İleri yaş ve komorbid hastalıklar nedeni ile tıbbi onkoloji kliniği değerlendirmesinde de hastaya eş zamanlı ve konsolidasyon kemoterapisi verilmesi uygun bulunmadi.

Hastamızın onamı alındıktan sonra 20 Ekim 2010 ile 6 Aralık 2010 tarihleri arasında sağ akciğere ve mediastene yönelik 66 Gy/ 33 fraksiyon konformal RT, 3 Şubat 2011 ile 24 Mart 2011 tarihleri arasinda prostat ve pelvik lenf nodlarına yönelik 72 Gy/ 36 fraksiyon konformal RT uygulandi.

Takip 3 aylık aralıklar ile yapıldı. Takip süresi akciğer RT'sinden sonra 33 ay, pelvik RT'den sonra 29 aydi. Pelvik RT sonrası ilk kontrolde PSA düzeyi $0.05 \mathrm{ng} / \mathrm{mL}$ ölçüldü, devam eden tetkiklerde de benzer olarak ölçüldü. Yirmi iki ay sonra çekilen toraks BT'de sağ akciğer üst lobda kitle izlenmedi, RT'ye sekonder değişiklikler görüldü (Resim 2a,2b). Son kontrolde çekilen akciğer grafide patolojik bulgu saptanmad, PSA değeri ise $0.04 \mathrm{ng} / \mathrm{mL}$ idi.

\section{Tartışma}

Aynı kişide birden fazla primer kanser olması ilk olarak geçen yüzyılda tanımlandı (3). Otopsi serilerinde multipl tümör oranları \%3.5 ile \%11 arasında değişmektedir (4). Multipl tümörler, tanı alma zamanına göre senkron ve metakron olarak sınıflandırılır. Senkron; eş zamanlı anlamina gelir ve iki primer kanser odağ 6 ay içinde tanı almıştır. Metakron ise ayrı zamanlı anlamına gelir ve iki kanserin tanı alış zamanları arası geçen süre 6 aydan daha uzundur (5).

Multipl tümörlerin rastlantısal olarak veya ilerleyen yaș ile artmış kanser sıklığına bağlı veya her iki tümörün ortak etyolojiye sahip olmasına bağlı olarak ortaya çıktığı yönünde görüşler vardır (6). Tanı ve takipte kullanılan radyolojik yöntemlere bağl1 kümülatif radyasyon yükünün ve tedavide kullanılan bazı kemoteropötiklerin veya RT'nin ikincil malignensi gelişimine neden olduğu gösterilmiştir (7). Aile öyküsü olması, ailesel sendromlar, immünsüpresyon yapan hastalıklar da yine multipl primer kanserin etyolojisinde bulunan diğer faktörlerdir. Gelişmiş tanı yöntemleri, kanser tedavisindeki başarılar, artmış yaşlı popülasyon ve yaşam beklentisi multipl primer kanser tanis1 insidansındaki artış ile ilişkilidir (7).

Maligniteli bir olguda ikinci primer olarak akciğer malignitesi görülme insidans $\% 1.6$ ile \%3 arasındadır (1). Sıklıkla ise üst solunum ve üst sindirim sistemi maligniteleri ile birliktedir (8-10). Baş boyun kanserleri ile ikinci primer olarak akciğer malignitesinin senkron görülme insidansı \%1 iken, sigaranın ortak etyoloji olduğu bu malignitelerin metakron görülme sıklığ $\% 10$ kadardır $(9,10)$. Akciğer kanseri, böbrek ve renal pelvis kanserleri gibi ürolojik kanserler ile birlikte görülebilir $(9,10)$.

Eş zamanlı olarak iki ayrı primer malignite saptandığında tedavi önceliğ̀i tümörlerin ciddiyetine göre belirlenir. Klinik 
evre ve hastanın performans durumu tedavi kararını belirleyen diğer faktörlerdir. Daha agresif seyirli olan tümör öncelikli olarak tedavi edilir, ardından ikinci malignitenin tedavisi düzenlenir (3). Olgumuzda da öncelikle daha agresif seyirli olan akciğer kanseri tedavisi yapıldıktan sonra hastanın genel durumunun düzelmesi ile prostat kanserine yönelik tedavisi yapıldı. Hasta her iki tedaviyi de iyi tolere etti. Takip süresi akciğer RT'sinden sonra 33 ay, pelvik RT'den sonra 29 aydi. Son kontrolde uygulanan tedavilere tam yanıt alındığı izlendi.

Sonuç olarak, genel sağkalım üzerine erken teşhis prognostik öneme sahip olduğundan, kanser tanısı almış bir hastada mevcut olan veya sonradan gözlenen kitlelerin metastaz dışında ikinci bir kanser odağına ait olabileceği klinisyenlerce her zaman akılda tutulmalıdir.

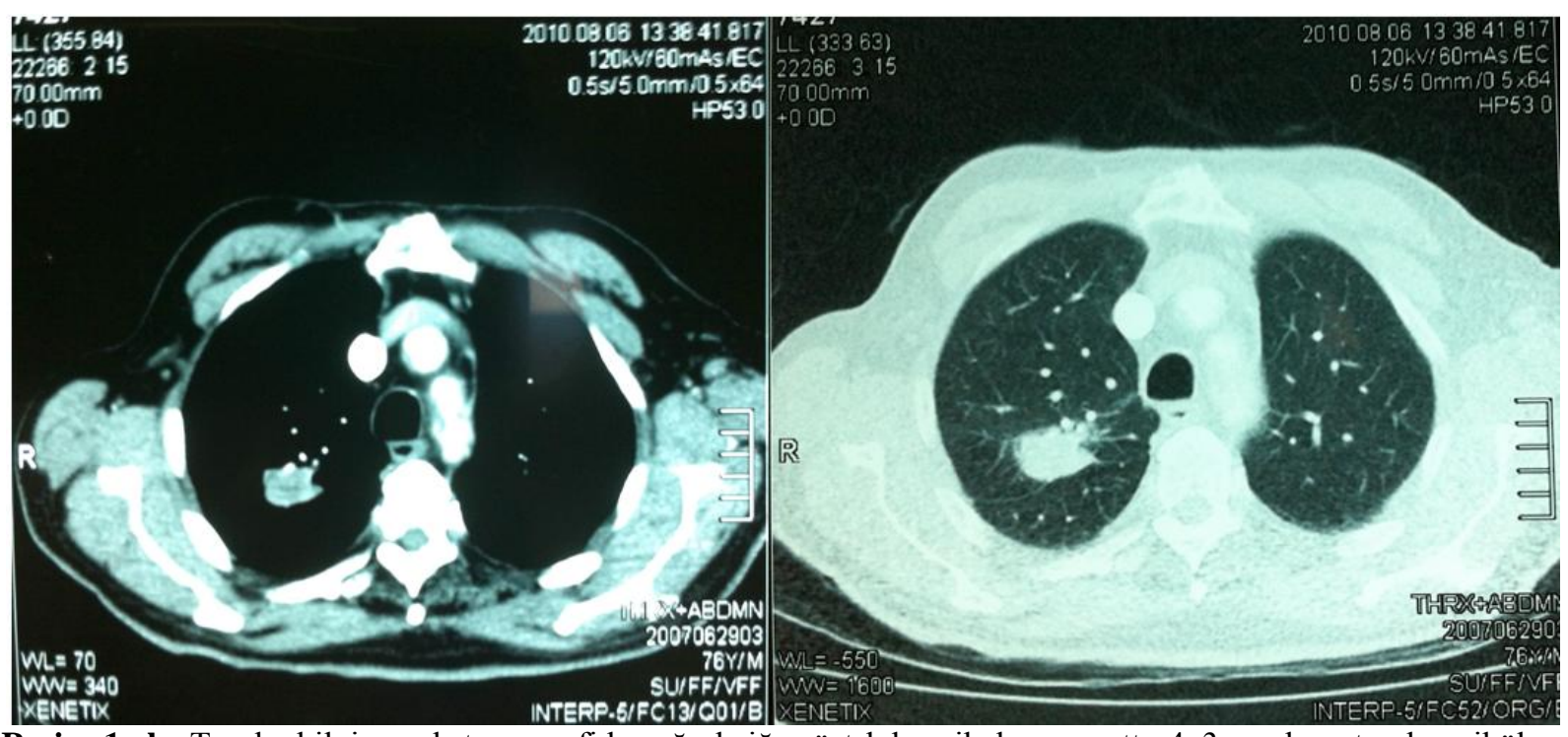

Resim 1a,b; Toraks bilgisayarlı tomografide sağ akciğer üst lob apikal segmentte $4 \times 3 \mathrm{~cm}$ boyutunda spiküler kitle

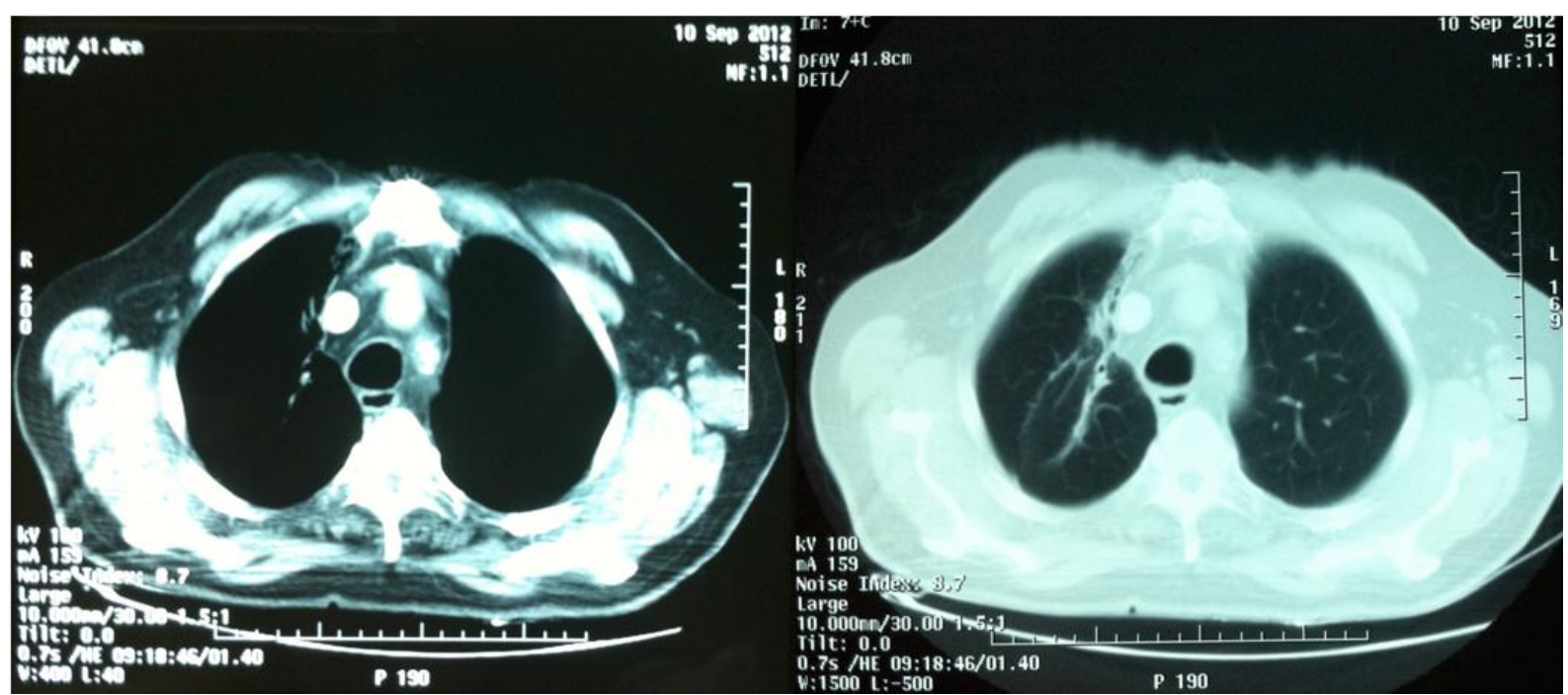

Resim 2a,b; Toraks bilgisayarlı tomografide sağ akciğer üst lobda radyoterapiye sekonder değişiklikler

\section{Çıkar Çatışması: Yok}

\section{Kaynaklar}

1. Baççıŏlu Kavut A, Kalpaklıoğlu F, Ayva Ş, Batislam E. A Rare Synchronous Tumor Combination of Primary Squamous Cell Lung
Cancer and Urinary Papillary Cell Carcinoma. Tur Toraks Der 2011;12:120-3

2. Fleisher AG, McElvaney G, Robinson CL. Multiple primary bronchogenic carcinomas: treatment and follow-up. Ann Thorac Surg 1991;51:48-51

3. Billroth T. General surgical pathology and therapy. Guidance for students and physicians. Lecture. Khirurgiia (Mosk) 1991;10:136-43

Address for Correspondence: Uzm. Dr. Ela Delikgöz Soykut, Erzurum Bölge Eğitim Araştırma Hastanesieski Numune Erzurum - Türkiye

Available at: www.actaoncologicaturcica.com 
4. İnci O, Aydın S, Ereselli H, Kaya E. İki primer tümörlü olgular. Double primary tumoral cases. Türk Üroloji Dergisi 1994;20:44-7

5. Kapsinow R. Multiple primary cancer. A classification with report of cases. J La State Med Soc 1962;114:194-200

6. Moore R, Tsukada Y, Regelson W, Pickren JW., Bross ID. Synchronous tumors in patients with multiple primary cancers. Cancer 1965;18:1423-30

7. Sonneveld P, Kurth KH, Hagemeyer A, Abels J. Secondary hematologic neoplasm after intravesical chemotherapy for superficial bladder carcinoma. Cancer 1990;65:23-5
8. Lippman SM, Benner SE, Hong WK. Retinoid chemoprevention studies in upper aerodigestive tract and lung carcinogenesis. Cancer Res 1994;54 (Suppl 7):2025-8.

9. Skov T, Sprogel P, Engholm G, Frolund C. Cancer of the lung cancer and urinary bladder in Denmark, 1943-87: a cohort analysis. Cancer Causes Control 1991;2:365-9

10. Salminen E, Pukkala E, Teppo L. Bladder cancer and the risk of smoking-related cancers during follow up. J Urol 1994;152:1420-3 